against a disk of polished metal with slightly elliptic rim, producing in either case a bell fringed all round its circumference and lacking transparency.

The bell to which we here call attention is distinguished by the way in which it causes the liquid vein to expand as soon as it reaches the orifice of the ajutage. Instead of making it strike against a metal plate, the surface of which, however carefully polished, always betrays some imperfection, M. E. Bourdon brings an antagonistic column of water to bear on it, so that the jet expands and falls into the basin, forming a bell as clear as crystal and impervious enough to cut off all communication between the interior and circumambient air.
The pipe conducting the water from the reservoir ends in a truncated form of nozzle, of about 12 degrees of angular opening, in such a way as to make all the threads of water converge towards the middle of the jet. Over this is placed concentrically to the truncated nozzle a glass tube of about $20 \mathrm{~cm}$. in length, and of the same interior diameter as that of the orifice by which the water rises from the reservoir. This antagonistic tube, as it may be called, has to be supported by a copper rod fixed either against a wall or on the margin of the basin, at a distance of $2 \mathrm{~cm}$. between its lower extremity and the truncated appendage. The reservoir must be kept at a constant level by means of a water-gauge cock. The

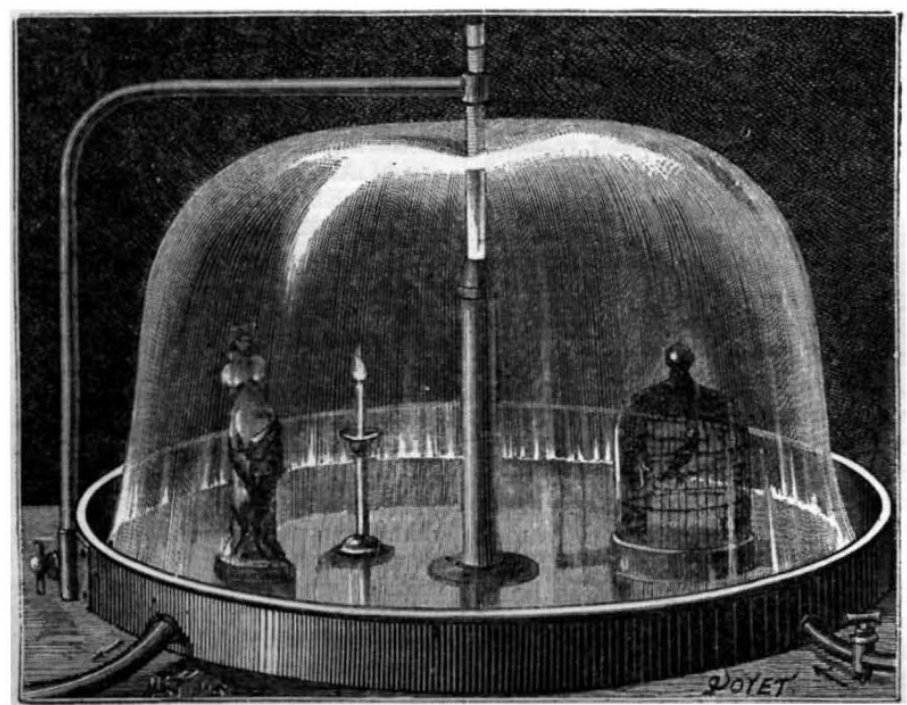

water-height above the jet will be about $60 \mathrm{~cm}$. The flow of the water or its stoppage will of course be regulated by a cock.

The apparatus so arranged and the basin filled with water to the level of the overflow, the cock will be gently opened, and the water traversing the interval between the ajutage and the antagonistic tube will rise a few centimetres high in the latter. A ball of ovoidal shape will then come to view. By opening the cock very slowly its diameter will gradually enlarge till the bell assumes the form of a hemisphere. At this point let the opening of the cock be reduced a very little, and the bell will change its shape; its rim will become lowered to the plane of the water of the basin, and its profile will show a bell similar to the gardener's bell glass.

By placing a very thin copper wire vertically towards the top of the bell, a vertical incision may be made in the bell, parting it into two separate sides. Through the gap thus formed, a statuette, a lighted candle, or a cage containing a bird, may be introduced inside the bell without wetting it. The tubes hitherto used have not exceeded $20 \mathrm{~mm}$. in diameter; but by employing apparatus of much larger dimensions, water bells of from 3 to 4 metres in diameter might be produced just as perfect as those of from 60 to 80 centimetres, and under which people might walk about or lounge at pleasure.

\section{SCIENCE AND THE SANDHURST EXAMINATIONS}

W

$\mathrm{E}$ have now before us the revised regulations for the examinations of candidates for admission to the Royal Military College, Sandhurst. Up to and including the summer examination of 1885 the present scheme is to remain in force. Under it Mathematics, English History, and Latin receive 3000 marks each; Greek, French, German, Experimental Science, General and Physical Geography and Geology count 2000 marks each. Candidates are left free to select any four of these subjects. They may also take up drawing, for which I 500 marks are given. After the summer of 1885 the subjects are to be grouped and marked as follows :-

$\begin{array}{ccccc} & & & & \\ \text { ClaAsS I. - Marks } \\ \text { 2. Mathematics } & \ldots & \ldots & \ldots & 3000 \\ \text { 3. French } \ldots & \ldots & \ldots & \ldots & 3000 \\ \text { 4. German ... } & \ldots & \ldots & \ldots & 3000 \\ \end{array}$

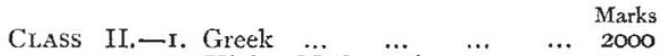

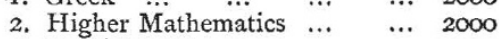

$$
\begin{aligned}
& \text { 3. English History } \quad \ldots . \quad \ldots .2000 \\
& \text { 4. Experimental Sciences } \ldots . .2000 \\
& \text { 5. Physical Geography and Geology } 2000 \\
& \text { Class III.-I. English Composition } \ldots \quad \ldots \quad 500 \\
& \text { 2. Drawing, Freehand } \ldots \quad \ldots \quad 500 \\
& \text { 3. ", Geometrical ... ... } 500
\end{aligned}
$$

Of these subjects candidates must take up three from Class I., and may take up either the remaining subject in Class I. or any one subject in Class II., and may also take up all the subjects in Class III.

These figures speak for themselves. Science is now placed on an equal footing with Greek and Higher Mathematics, \&c., and its position is therefore somewhat improved as compared with that assigned to it in the proposals of a few months since. In the mair, however, the revised scheme cannot be satisfactory to any one who has the interests of education at heart. 
After our article of June 26 (p. I 89) it is needless to go much further into detail, but it may be pointed out that hitherto certain subjects, of which Science is one, have had 2000 marks each, whilst three others have had 3000 , and free choice of four subjects among these has been allowed. Owing to the great influence which marks have naturally exercised upon the choice of candidates and to other circumstances, the position of Science has been modest enough. In future, however, it will have (to put it numerically) about one-fourth of its previous chance, since, instead of the candidates being free to select four subjects, they will now only be free to select one. In short the final arrangements, though undoubtedly improvements upon those announced a few months since, and in one particular considerable improvements, are in their main features retrograde and unsound. They will hamper those of our schools which make it their aim to widen the basis of education in this country by the introduction of science into their regular work, and they will further discourage those who have hitherto hesitated from following their example. They will be a check on freedom and progress in education. The new regulations no doubt will encourage the study of modern languages. They do this, however, at too great a cost to other subjects of at least equal importance. We regret very much that the War Office authorities have not adopted some plan by which, whilst securing a knowledge of those subjects which they regard as professionally essential, they would have left a fairer field to such studies as Higher Mathematics, Natural Science, Greek, \&c. Whilst we regret so much the blow to science teaching in our schools which is given by the final adoption of the scheme before us, and that young men of scientific capacity should stand so poor a chance of employment in our military services, we must acknowledge that in their revised regulations the War Office authorities have effected a distinct improvement by the new grouping of the experimental sciences and the addition of a practical examination to each group; although, from the greatly inferior position which science will hold in future, we fear that the practical advantage in the Sandhurst examinations will be very small. If, however, such a grouping of the natural sciences could be extended to the Woolwich examination also, it would be a great gain. The allotment of marks at present in force in the Woolwich competitions deals very fairly with the various subjects. Mathematics and Drawing, which are of special importance, are duly encouraged, whilst a fair liberty of choice among other subjects is left to the candidates. It has, however, been a complaint that, owing to the unequal difficulties presented by the present groups, some science subjects are unduly encouraged at the cost of others. This complaint ought practically to cease under such a classification as is now introduced into the Sandhurst scheme, for it ought no longer to be difficult for the examiners to set papers of fairly equal difficulty and range. We hope this change of detail may be extended to the science of the Woolwich examinations. We believe it would be welcomed by all those who have the interests of science teaching at heart.

\section{THE BRITISH ASSOCIATION}

THE fifty-fourth annual meeting of the British Association commenced yesterday at Montreal. About 800 members have arrived in Montreal from England, and the interest taken in the meeting both in Canada and the United States is evidenced by the great number of visitors which it has attracted to that city. The reception accorded to the Association both by the city and the Dominion is all that could be wished. Montreal itself has raised a fund of 40,000 dollars for expenses, and over 300 members have been received as guests into private houses. McGill College, where the Association meets, has been specially prepared for the purpose, and there is every probability that the meeting will be a success in all respects.

The proceedings began last night with the address of the President, Lord Rayleigh, who was to be introduced by Sir William Thomson. To-day the Sectional proceedings began, and it will be seen from what follows that the addresses are quite up to the average. To-morrow evening Prof. Lodge delivers his lecture on "Dust"; on Saturday Prof. R. S. Ball gives the popular lecture, his subject being "Comets"; and on Monday evening Dr. Dallinger gives a richly illustrated account of the lowest forms of life.

Extensive arrangements have been made for excursions of the members to Quebec, Ottawa, and other places of interest in the Dominion and the United States, with garden parties, soirées, and receptions, in the intervals of the meetings. The citizens of Quebec are arranging to entertain 600 members on Saturday.

Inaugural Address by the Right Hon. Lord Rayleigh, M.A., D.C.L., F.R.S., F.R.A.S., F.R.G.S., PROFESSOR of Experimental Physics in the University of CAMbridge, President

IT is no ordinary meeting of the British Association which I have now the honour of addressing. For more than fifty years the Association has held its autumn gathering in various towns of the United Kingdom, and within those limits there is, I suppose, no place of importance which we have not visited. Anc now, not satisfied with past successes, we are seeking new worlds to conquer. When it was first proposed to visit Canada, there were some who viewed the project with hesitation. For my own part, I never quite understood the grounds of their apprehension. Perhaps they feared the thin end of the wedge. When once the principle was admitted, there was no knowing to what it might lead. So rapid is the development of the British Empire, that the time might come when a visit to such out-of-the-way places as London or Manchester could no longer be claimed as a right, but only asked for as a concession to the susceptibilities of the English. But seriously, whatever objections may have at first been felt soon were outweighed by the consideration of the magnificent opportunities which your hospitality affords of extending the sphere of our influence and of becoming acquainted with a part of the Oueen's dominion which, associated with splendid memories of the past, is advancing daily by leaps and bounds to a position of importance such as not long ago was scarcely dreamed of. For myself, I am not a stranger to your shores. I remember well the impression made upon me, seventeen years ago, by the wild rapids of the St. Lawrence, and the gloomy grandeur of the Saguenay. If anything impressed me more, it was the kindness with which I was received by yourselves, and which I doubt not will be again extended not merely to myself but to all the English members of the Association. I am confident that those who have made up their minds to cross the ocean will not repent their decision, and that, apart altogether from scientific interests, great advantage may be expected from this visit. We Englishmen ought to know more than we do of matters relating to the Colonies, and anything which tends to bring the various parts of the Empire into closer contact can hardly be over-valued. It is pleasant to think that this Association is the means of furthering an object which should be dear to the hearts of all of us; and I venture to say that a large proportion of the visitors to this country will be astonished by what they see, and will carry home an impression which time will not readily efface.

To be connected with this meeting is to me a great honour. but also a great responsibility. In one respect, especially, I feel that the Association might have done well to choose another President. My own tastes have led me to study mathematics and physics rather than geology and biology, to which naturally more attention turns in a new country, presenting as it does a fresh ficld for investigation. A chronicle of achievements in these departments by workers from among yourselves would have been suitable to the occasion, but could not come from me. If you would have preferred a different subject for this address, I hope at least that you will not hold me entirely responsible.

At annual gatherings like ours the pleasure with which friends meet friends again is sadly marred by the absence of those who can never more take their part in our proceedings. Last year my predecessor in this office had to lament the untimely Joss of 